\title{
SEISMIC TESTING OF ADJACENT INTERACTING MASONRY STRUCTURES
}

\section{Igor Tomić $^{1 *}$, Andrea Penna ${ }^{2}$, Matthew DeJong ${ }^{3}$, Christoph Butenweg ${ }^{4}$, A.A. Correia ${ }^{5}$, P.X. Candeias ${ }^{5}$, Ilaria Senaldi ${ }^{2}$, Gabriele Guerrini ${ }^{5}$, Daniele Malomo ${ }^{3}$, Katrin Beyer ${ }^{1}$}

${ }^{1}$ École Polytechnique Fédérale de Lausanne (EPFL), School of Architecture, Civil an Environmental Engineering (ENAC)

Lausanne, Switzerland igor.tomic@epfl.ch

${ }^{2}$ University of Pavia, Department of Civil Engineering and Architecture (DICAr) Pavia, Italy

${ }^{3}$ University of California Berkeley, Civil and Environmental Engineering Berkeley, United States

${ }^{4}$ RWTH Aachen University, Center for Wind and Earthquake Engineering Aachen, Germany

${ }^{5}$ National Laboratory for Civil Engineering (LNEC) Lisboa, Portugal

${ }^{6}$ EUCENTRE European Centre for Training and Research in Earthquake Engineering Pavia, Italy

Keywords: Historical centres; Stone masonry; Adjacent buildings; Shake table test

\begin{abstract}
In many historical centres in Europe, stone masonry buildings are part of building aggregates, which developed when the layout of the city or village was densified. In these aggregates, adjacent buildings share structural walls to support floors and roofs. Meanwhile, the masonry walls of the façades of adjacent buildings are often connected by dry joints since adjacent buildings were constructed at different times. Observations after for example the recent Central Italy earthquakes showed that the dry joints between the building units were often the first elements to be damaged. As a result, the joints opened up leading to pounding between the building units and a complicated interaction at floor and roof beam supports.

The analysis of such building aggregates is very challenging and modelling guidelines do not exist. Advances in the development of analysis methods have been impeded by the lack of experimental data on the seismic response of such aggregates. The objective of the project AIMS (Seismic Testing of Adjacent Interacting Masonry Structures), included in the H2020 project SERA, is to provide such experimental data by testing an aggregate of two buildings under two horizontal components of dynamic excitation. The test unit is built at half-scale, with a two-storey building and a one-storey building. The buildings share one common wall while the façade walls are connected by dry joints. The floors are at different heights leading to a complex dynamic response of this smallest possible building aggregate. The shake table test is conducted at the LNEC seismic testing facility.

The testing sequence comprises four levels of shaking: $25 \%, 50 \%, 75 \%$ and $100 \%$ of nominal shaking table capacity. Extensive instrumentation, including accelerometers, displacement transducers and optical measurement systems, provides detailed information on the building aggregate response. Special attention is paid to the interface opening, the global behaviour in relation to the interface separation, interstorey drifts and out-of-plane displacements.
\end{abstract}




\section{INTRODUCTION}

Historical city centres throughout Europe are often characterized by masonry building aggregates which have usually developed without consistent planning or engineering over a long course of time. In order to save space and resources, units can share a structural wall, with the facades of adjacent buildings often connected by dry joints. Furthermore, due to the continuous development through the centuries, it is common for the adjacent buildings to have different material properties, distribution of openings and floor and roof heights (Figure 1). As shown by the recent earthquakes in Italy, the opening of the joint can lead to very complex behaviour and interaction of the units. The analysis of masonry building aggregates poses numerous challenges, with clear and detailed modelling guidelines not being present in the literature and codes. One of the principal reasons is the lack of experimental data, due to the high cost and the complexity of performing tests on large-scale aggregates.
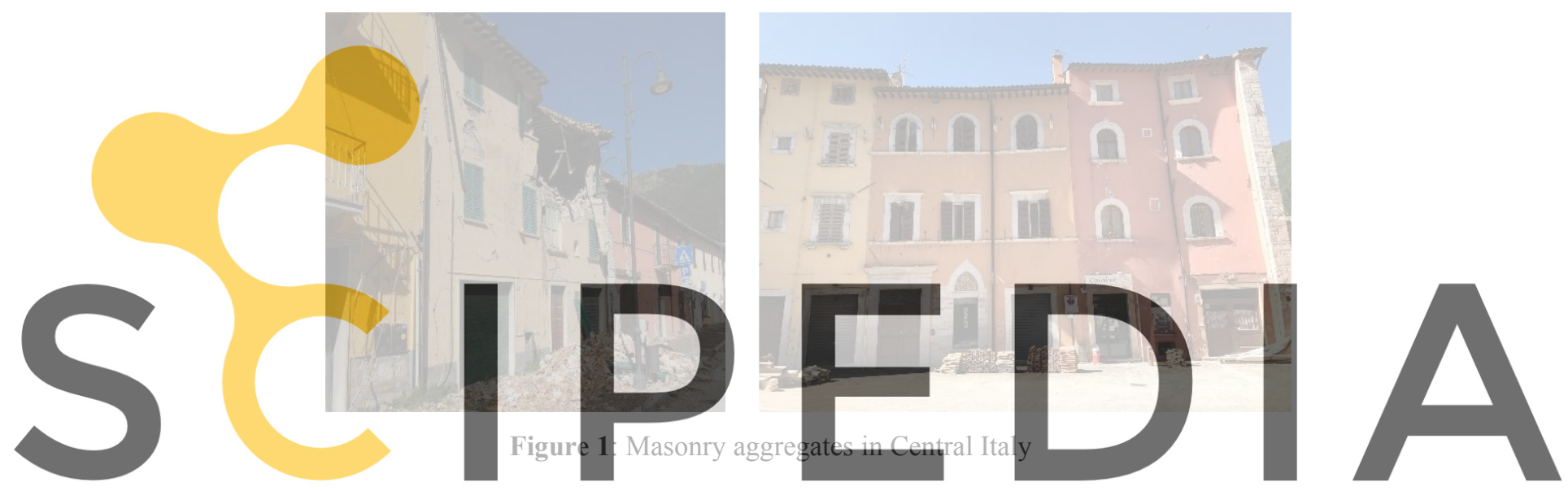

Experimental data on masonry aggregates has been limited to one large scale campaign,

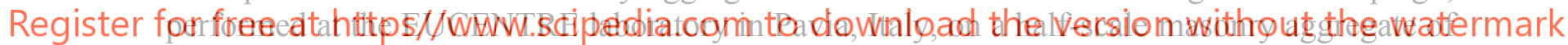
similar typology [1,2]. The uni-directional shake table test was performed with incremental PGA stages before reaching significant damage. Afterwards, the specimen was retrofitted and the increasing PGA stages were repeated [3]. The test provided valuable insight into the behaviour of masonry aggregates, but no full separation has occurred at the unit interface before the ultimate limit state was reached because the floor diaphragms of the two units were connected also in the initial configuration.

Various authors have performed numerical analyses on masonry aggregates on a different scale of modelling detail. The macro-element approach using Tremuri software [4] was used in [5] to better understand the vulnerability of a single structural unit and its behaviour within building aggregates. Numerical and experimental results in terms of pushover and backbone curves, hysteretic responses and lateral displacement envelopes were compared in [6] to validate the macro-element approach in modelling masonry aggregates. Sophisticated numerical analysis results were used to set up a simple non-linear methodology by plotting simplified pushover curves of both single structural units and building compounds in [7]. Analyses results were compared to the Italian Guidelines on Cultural Heritage and correction factors proposed. A simplified assessment procedure was proposed for large scale seismic vulnerability assessment of masonry building aggregates [8]. Derived from the well-known 
vulnerability form for masonry buildings, it integrates five additional parameters to take into account the aggregate conditions among adjacent units. Theoretical and numerical approaches were used to evaluate the case studies in Central Italy $[9,10]$. The lack of experimental data makes it challenging to model the non-linear connection between the units of an aggregate with sufficient accuracy. In [11], the aggregate was modelled as a whole and as separate units with simple non-linear boundary conditions in order to evaluate the seismic behavior of both intermediate and end structural units.

\section{MOTIVATION AND OBJECTIVES}

The lack of experimental data has prompted a joint research programme between the École Polytechnique Fédérale de Lausanne (EPFL), Switzerland, University of Pavia, Italy, University of California, Berkeley, USA, RWTH Aachen University, Germany and the National Laboratory for Civil Engineering (LNEC), Portugal, named SERA AIMS - Adjacent Interacting Masonry Structures. As a part of this project, a shake table test is under preparation on a half-scale stone masonry building aggregate at the LNEC seismic testing facility. Complementary tests on materials and components are to be performed in parallel.

In order to contribute to the understanding of the masonry building aggregates behaviour, the test unit was designed according to the following set of objectives:

- Aiming for a large opening of the interface between Unit 1 (shorter) and Unit 2 (taller);

- Aiming for a global behaviour that is sensitive to the interface behavior (i.e. the
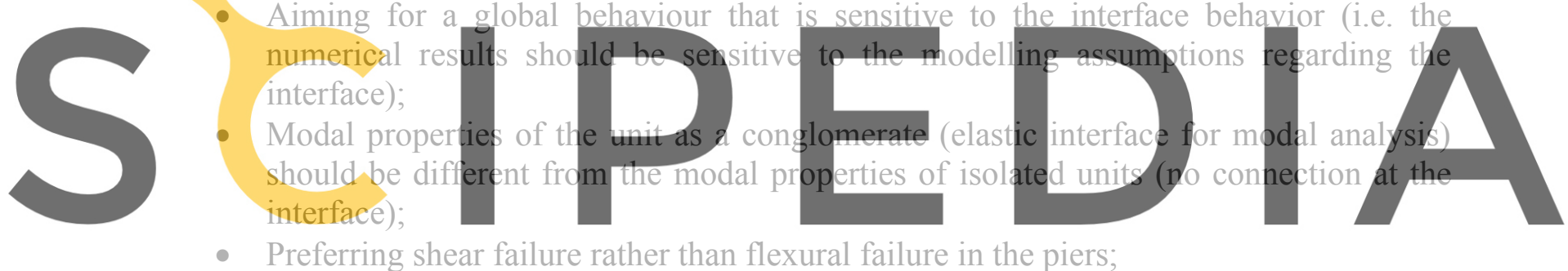

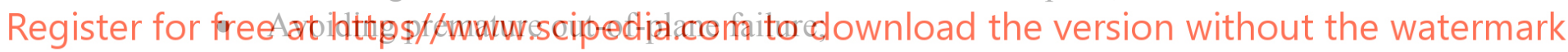

- Respecting the shake table limits in terms of weight and dimensions.

At the time of writing this article, the test unit is under construction. This article outlines the design objectives, the design process and the test set-up.

\section{CALIBRATION OF UNIT GEOMETRY}

In order to achieve the set of objectives, model calibration was performed using the OpenSees software [12], through a newly developed macro-element for modelling both inplane and out-of-plane dynamic behaviour [13]. Incremental dynamic analyses were run in order to select the geometry of the aggregate. First, four initial geometries were proposed, as shown in Figure 2, consisting of various combinations of unit dimensions and opening distributions. Out of the these four principal configurations, configuration 2 from Figure 2 was selected. 

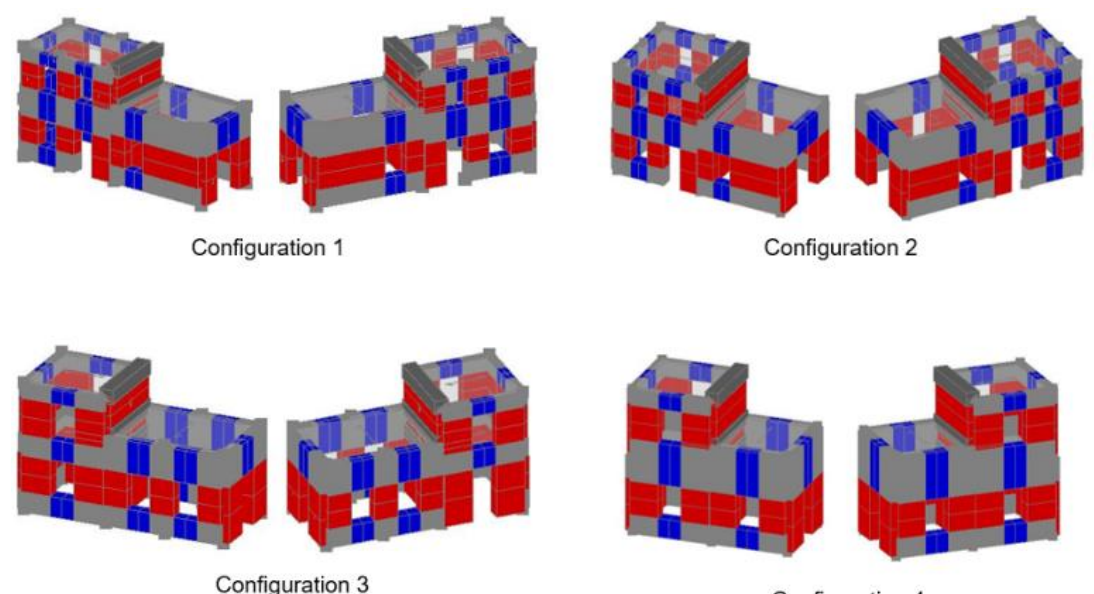

Configuration 4

Figure 2: Evolution of specimen geometry

After further iteration and calibration of the selected geometrical configuration, numerical analyses of the final geometry provide the modal properties of the elastic coupled and uncoupled structures, shown in Figure 3. For the eigenvalue analysis, the interface connecting the nodes of the two units is modelled as elastic in the coupled structure, whereas in the uncoupled case both units are modelled as completely separate structures. At the same time, the non-linear force-displacement simulated response in Figure 4 shows a significantly different behaviour of the building aggregate in terms of displacement demand for the model with a nonlinear interface and the model where the interface cannot open.

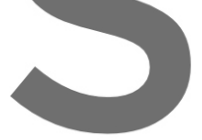

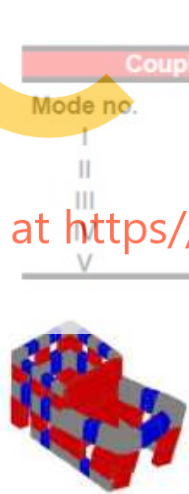

I

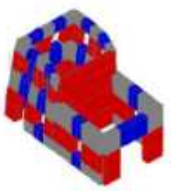

III

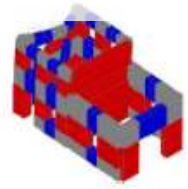

II

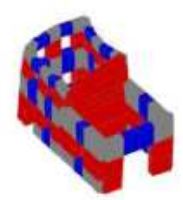

IV

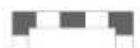

[UNIT 2 -
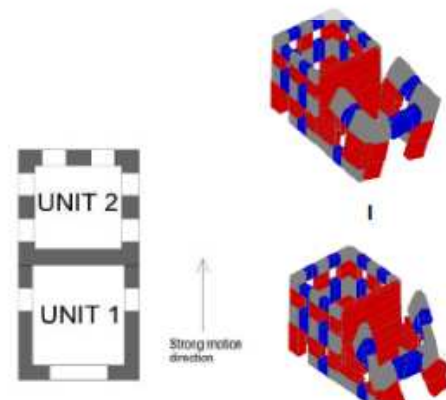

I

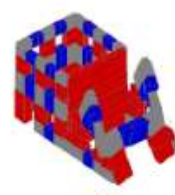

III

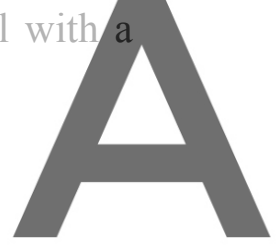

0.047 Unit $1 \mathrm{x}$ direction

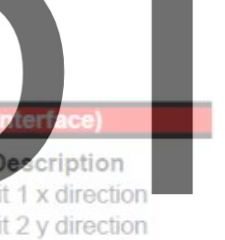

the watermark

load the versionzwithout the watermark

Figure 3: Comparison of modal properties between coupled and uncoupled structures 

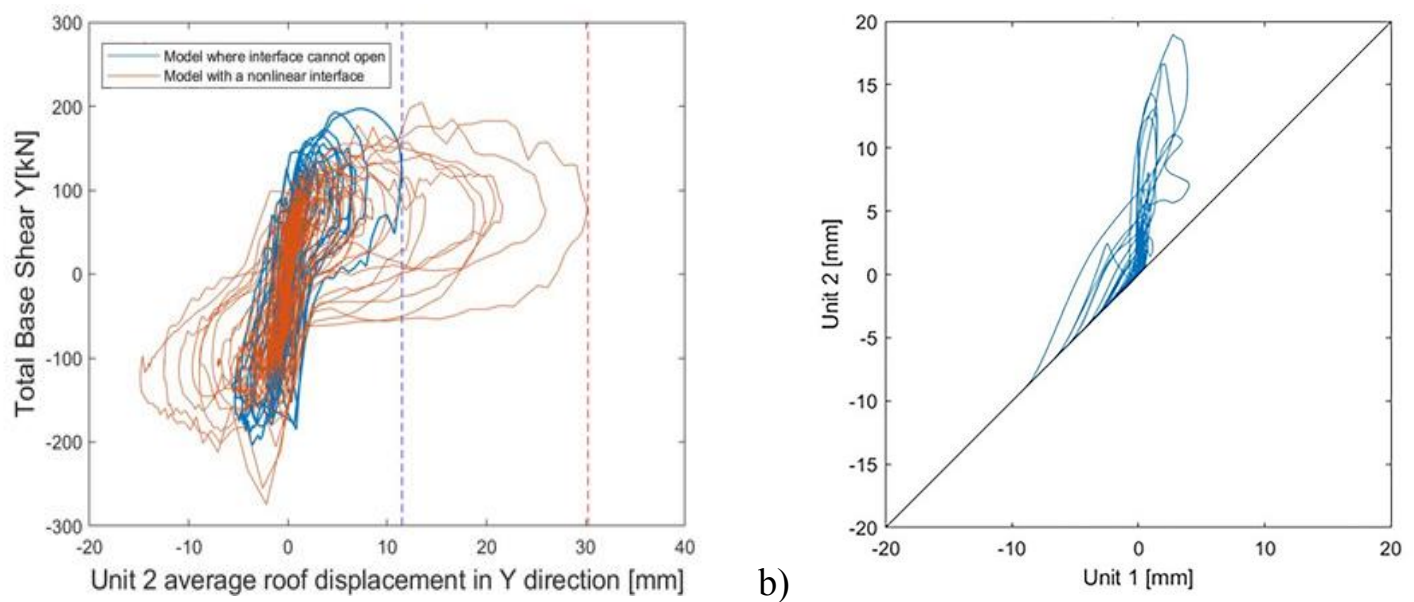

a)

b)

Figure 4: Predicted influence of interface behavior on global force-displacement response; b) Interface opening due to out-of-phase response

\section{SPECIMEN OVERVIEW}

The test specimen is a half-scale prototype of a masonry building aggregate. It is composed of two units, of which Unit 2 consists of two floors and Unit 1 of one floor, as can be seen in Figure 5. Unit 2 has a rectangular shape with four walls and plan outer dimensions of $2.5 \times 2.5$ $\mathrm{m}^{2}$. Unit 1 has a U-shape with three walls and plan outer dimensions of $2.5 \times 2.45 \mathrm{~m}^{2}$. The basic dimensions of the facades can be seen in Figure 6. Additional masses of 1.5 tons are even/y distributed per floor of Unit 2. There is no interlocking between the units, meaning that the interface between the two units is a dry joint. Walls are built of double-leaf stone masony in both units. The wall thickness of Unit 1 wall is $30 \mathrm{~cm}$ and the wall thicknesses of Unit 2 are 35 $\mathrm{cm}$ and $25 \mathrm{~cm}$ for the first and second floor, respectively. Underneath the openings, the thickness of the spandrels is decreased to $15 \mathrm{~cm}$. Timber diaphragms of the two units have

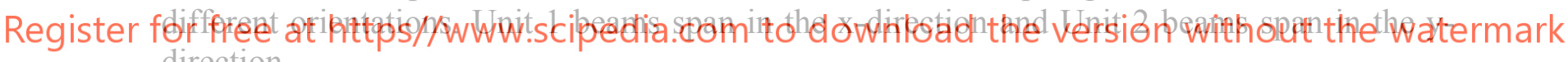
direction.

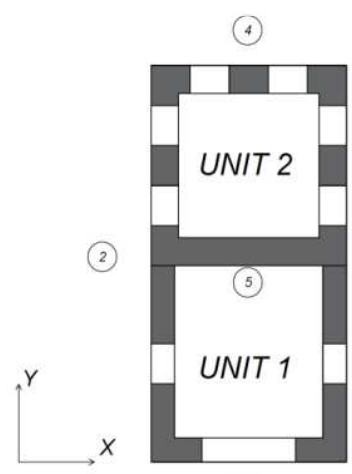

(1)
(3)

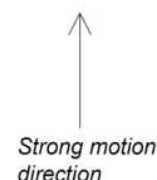
direction

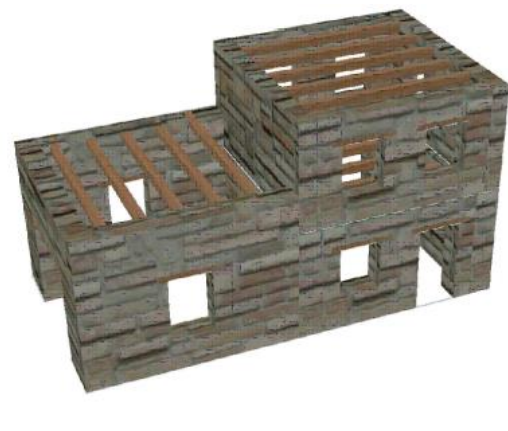

UNIT 1

UNIT 2

Figure 5: General unit orientation 


\subsection{Scaling factor}

The maximum payload of the shake table at LNEC imposed the construction of the prototype in half-scale. It has been common in the past experimental campaigns to use reduced scale specimens to research the seismic response of unreinforced masonry buildings. The most commonly used similitude relationships are Cauchy's or Cauchy-Froude's. However, using Cauchy's relationships would require scaling of gravity acceleration, which is not feasible. Using Cauchy-Froude's relationship would require increasing the density of the material, which would increase the total specimen weight. Because the specimen weight is the critical shaketable limitation, this was not a feasible option either. Instead, the stiffness and strength of the masonry material were reduced by a factor of $\lambda=2.0$. This was achieved by adding EPS spheres [2]. Therefore, the set of scale factors adopted is the same as the one used in $[1,2,3]$ and listed in Table 1.

Table 1: Scaling factors for the chosen similitude relationship [2]
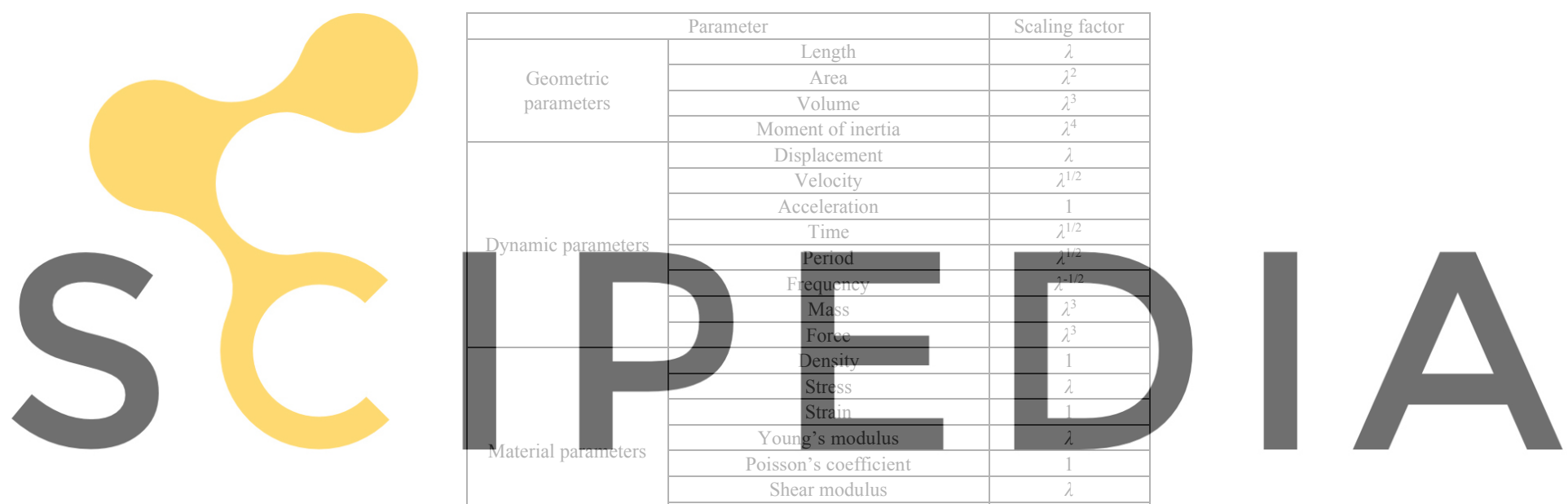

Register for free at https//www.scipedia.com to thownload the version without the watermark

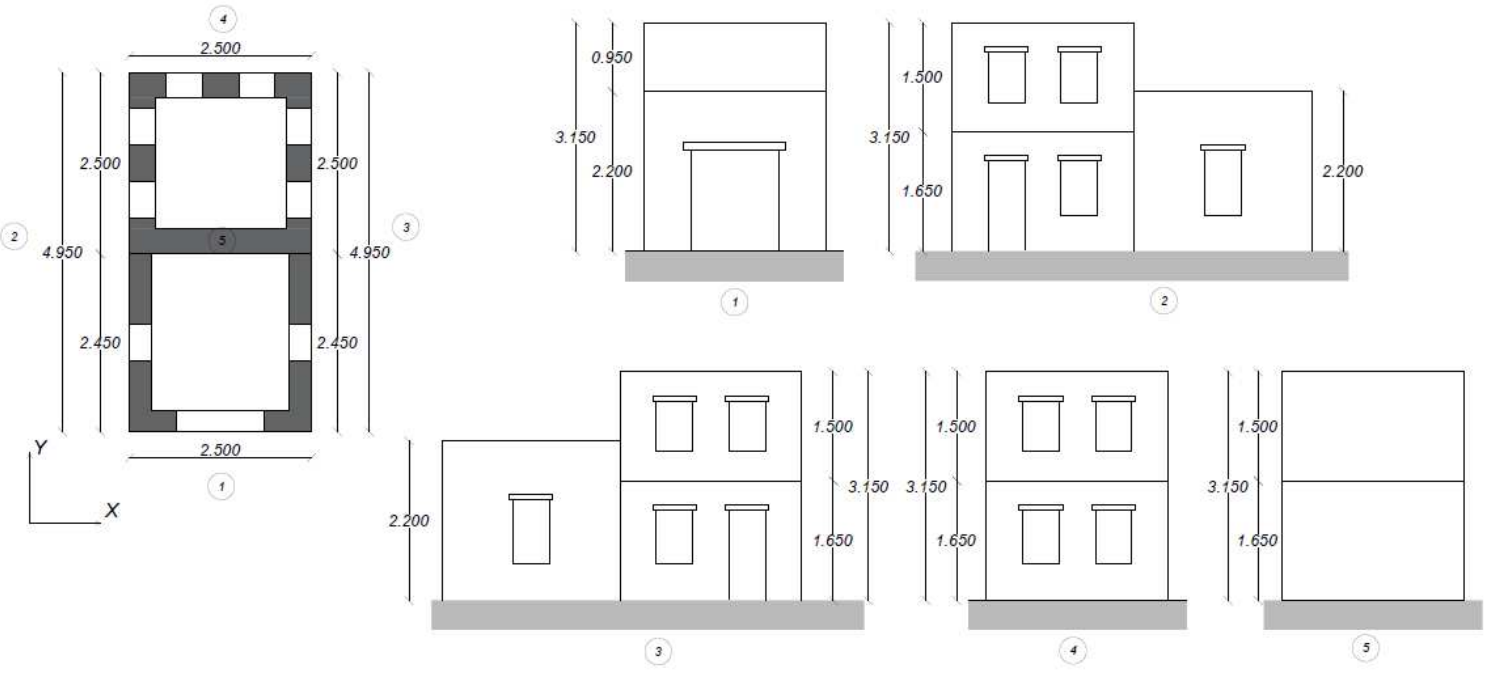

Figure 6: Elevation of the facades 


\subsection{Material properties and masonry typology}

To ensure comparability of results, the material for the construction of the stone masonry walls is, as much as possible, the same as the one used for the shake table test on the aggregate at the EUCENTRE [2], [3], which was also conducted at half-scale. For this reason, the masonry typology used at LNEC attempts to reproduce the one used at the EUCENTRE as much as possible and material properties for the prediction of the LNEC test were taken from [1]. In the campaign to be conducted at LNEC, material characterization tests will be performed on the mortar and masonry wallettes, while shear-compression tests on walls and material tests on stones were also performed at EUCENTRE and are reported in [1]. Due to the different stone quarries used, the LNEC specimen stones are more irregular, making the whole masonry typology less regular. The mortar is a commercial hydraulic lime mortar mix, with added EPS spheres in volumetric proportions 2:3 of EPS spheres to mixed mortar. EPS spheres lower the stiffness and strength of the mortar to satisfy the similitude relationships. Walls are constructed as double-leaf undressed stone masonry. Stones range in size from 10 to $25 \mathrm{~cm}$ and are arranged in horizontal courses which are not perfectly regular due to the irregularity of the stone. There is no interlocking between the leaves, except through stones placed at opening edges and building corners. Irregular broken stone pieces are used to fill the voids between the leaves, amounting to about $10 \%$ of proportional volume.
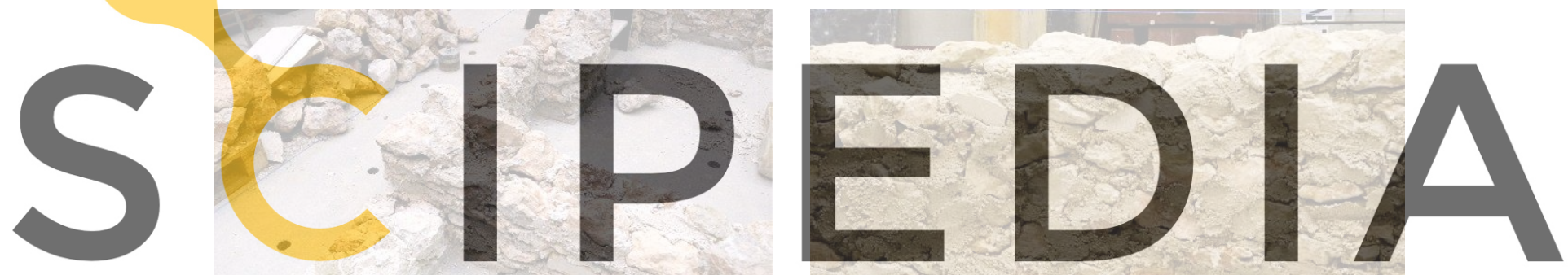

Register for free at https//www.scipedia.com to

download the version without the watermark

Figure 7: Masoniry typology

\subsection{Interface between the units}

The two structural units constituting the aggregate are connected by a dry joint. At the given height, first the Unit 2 and then the Unit 1 is constructed to ensure that there is no interlocking between the units. Before the construction of the Unit 1, the contact surface of the Unit 2 is smoothened with a mortar layer to ensure no interlocking between the walls. There are no protruding stones at the interface of the two units. This type of connection, paired with different modal properties of two units should ensure separation and out-of-phase behavior during the test.

\subsection{Floors}

The building prototype includes flexible timber floors. Floors are composed of wooden beams with cross-sections of $8 \times 16 \mathrm{~cm}^{2}$ and a single layer of perpendicularly placed $2 \mathrm{~cm}$ thick planks, connected by two nails at each intersection. Timber beams span in different directions, 
with Unit 1 beams spanning in $\mathrm{x}$-direction and Unit 2 floors in the $\mathrm{y}$-direction (the coordinate system is defined in Figure 6). The different orientation of beams is chosen to facilitate different behavior of units when subjected to bi-directional earthquake record. PVC tubes are placed in the walls at the end of each beam and longitudinally alongside each end-beam. If the building exhibits a behavior likely to lead to premature out-of-plane failure, these PVC tubes will be used together with steel angles and threaded rods to anchor the beams into the walls. These steel angles will be placed at the end of each beam and longitudinally along each beam next to a wall. They will not be anchored to the walls at the beginning of the test and are not expected to influence the behavior of the test buildings. They might be activated only in later phases of the test if a premature out-of-plane failure is anticipated. They are also activated during the transportation of the test unit from the lab floor onto the shake table.

\subsection{Masses}

Besides the mass of the units and of the steel-concrete foundation, an additional 1.5 tons per floor have been placed on Unit 2 in order to increase the differences in modal properties between the units, while respecting the payload limits of the shake table. The objective was to increase the periods of vibration of Unit 2, which is, at the start of the test, the more flexible unit. Additional masses are applied through steel plates, firmly attached to the floors of Unit 2 to prevent sliding. Table 2 presents the masses of the specimen components.
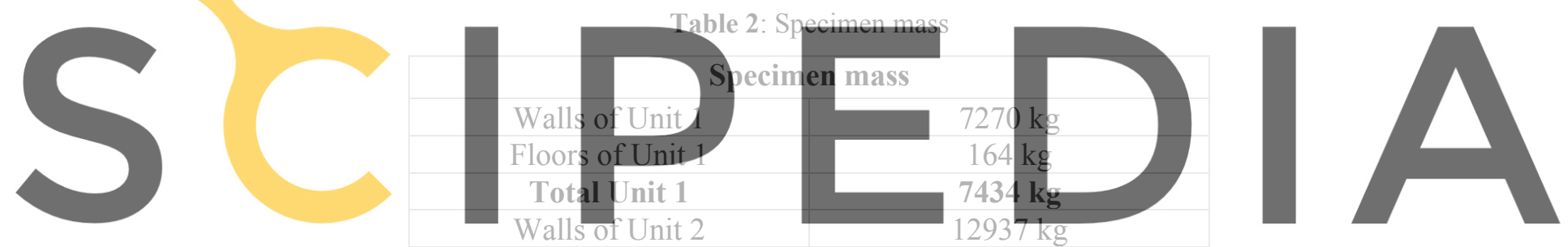

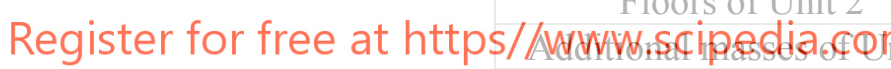

$335 \mathrm{~kg}$

\begin{tabular}{|c|c|}
\hline Total Unit 2 & $16272 \mathrm{~kg}$ \\
\hline Steel-concrete foundation & $18000 \mathrm{~kg}$ \\
\hline TOTAL & $\mathbf{4 1 7 0 6} \mathbf{~ k g}$ \\
\hline
\end{tabular}

\section{SEISMIC INPUT AND LOADING SEQUENCE}

The specimen will be tested under one and two-component excitations, using the two horizontal components (Figure 8.) of the Albatros station records of the 1979 Montenegro earthquake [14]. Nominal maximum accelerations that will be applied by the shake table to the specimen are $0.875 \mathrm{~g}$ in the $\mathrm{y}$-direction and $0.625 \mathrm{~g}$ in the $\mathrm{x}$-direction. The specified limit is reached in four steps, with the ground motion applied at 25\%,50\%, 75\% and 100\% of such limit. Each step consists of three stages, comprising first a uni-directional test in the y-direction, followed by a uni-directional test in the x-direction and finally, a bi-directional test in both $\mathrm{x}$ and y-directions. Intermediate dynamic identification tests will be carried out in order to track the modal properties of the units. The time step will be scaled with $\lambda^{1 / 2}$, as defined in Chapter 4.1. 


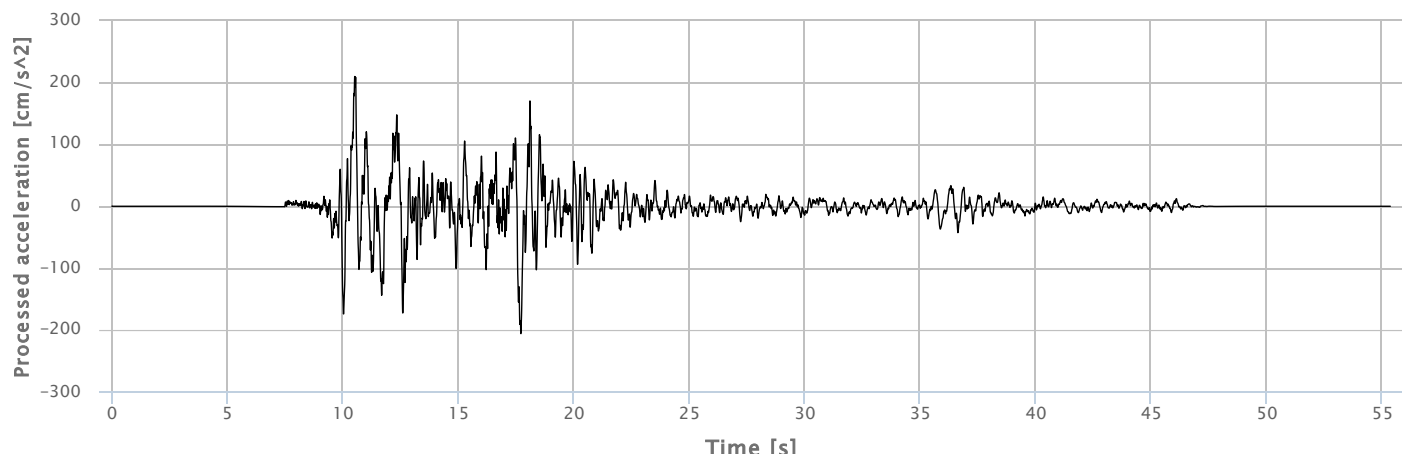

a)

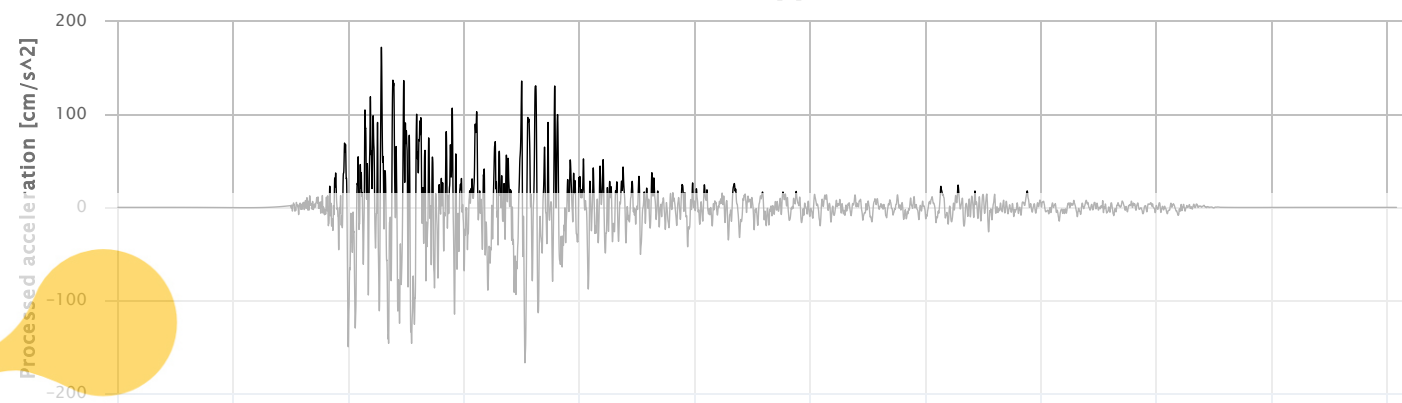

b)

Figure 8: Montenegro 1979. Albatros record processed accelerations: a) East-west direction; b) North-south
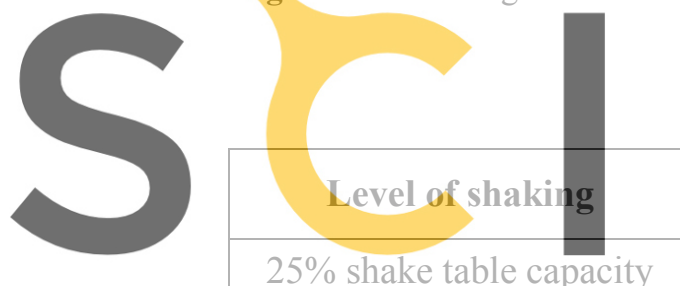

PGA $0.219 / 0.156 \mathrm{~g} \mathrm{y} / \mathrm{x}$-dir
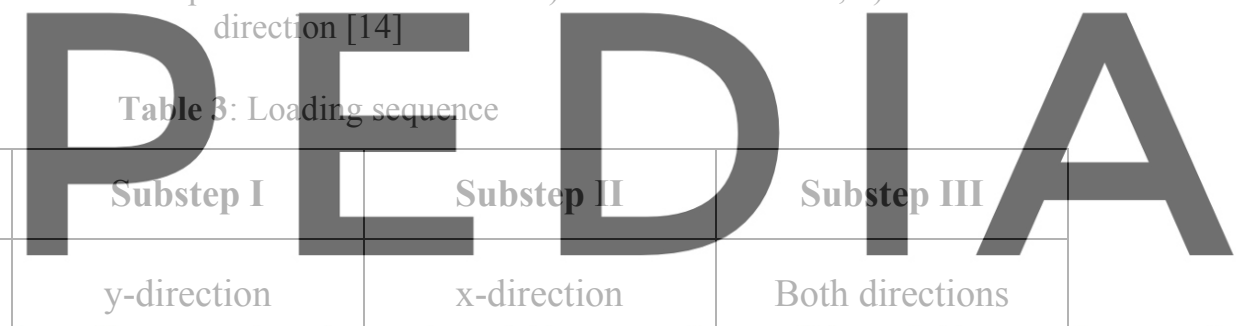

Register for free at https/\%WWW.scipedia.com to download the version without the watermark

\begin{tabular}{|l|c|c|c|}
$\begin{array}{l}50 \% \text { shake table capacity } \\
\text { PGA 0.438/0.313g y/x-dir }\end{array}$ & y-direction & x-direction & Both directions \\
\hline $\begin{array}{c}75 \% \text { shake table capacity } \\
\text { PGA 0.656/0.469g y/x-dir }\end{array}$ & y-direction & x-direction & Both directions \\
\hline $\begin{array}{l}\text { 100\% shake table capacity } \\
\text { PGA 0.875/0.625g y/x-dir }\end{array}$ & y-direction & x-direction & Both directions \\
\hline
\end{tabular}

\section{NUMERICAL PREDICTION}

To predict the response of the masonry building aggregate, a newly developed advanced macro-element [13] within the OpenSees framework [12] was used. The macro-element is formulated as a three-node and three-dimensional element, with a novel feature of capturing both the in-plane and out-of-plane dynamic behavior of masonry walls. All three cross-sections (at each node location) account for the combined in-plane and out-of-plane rocking. Explicit coupling of the flexural and shear response is modelled with the shear interface in the central section of the element. 
Elastic membrane elements are used to model floors, thus providing only the membrane stiffness components. The one-dimensional non-linear interface element is used to model the connections between walls of the same units, with the linear elastic behavior without crushing in compression, and finite tensile strength with exponential softening law. Floor to wall connections are modelled with "beam-slip" frictional interfaces. The strength of the interface is dependent on the friction coefficient and the acting vertical load on the interface. Pounding of the beams is captured by the material model when the slip is in negative direction. The connection between the two units of the aggregate is modelled with an n-dimensional zerolength element, as a frictional connection with a limited tensile and cohesive strengths with exponential degrading laws.

Due to the high number of non-linear interfaces and different material models implemented in the OpenSees model, multiple modeling uncertainties are present. Furthermore, due to the aleatory uncertainty of masonry as a material, a total number of 20 uncertain input parameters was detected. In order to evaluate them in a systematic manner, Latin Hypercube Sampling (LHS) has been performed, taking in total 300 sets of samples of the 20 input parameters. Then, taking advantage of the high computational efficiency of Equivalent Frame Models, Incremental Dynamic Analysis (IDA) was performed for each of the sets of samples. Based on the results, it was possible to derive a numerical fragility curve, as shown in Figure 9, accounting for the model uncertainty but considering a deterministic seismic input.
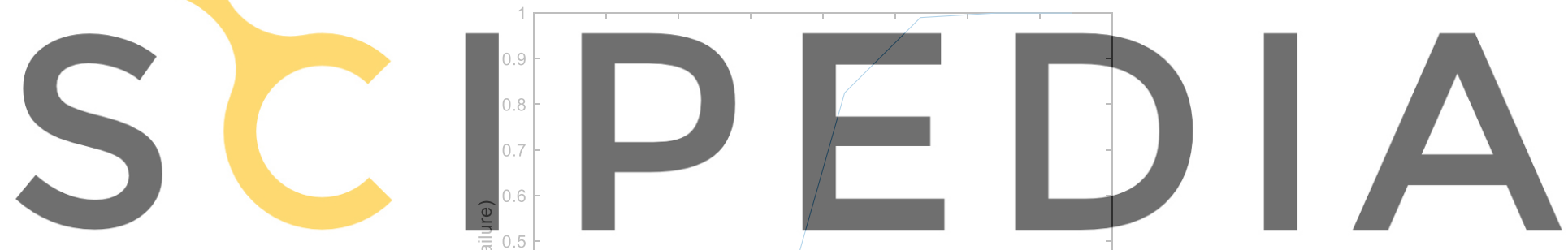

Register for free at https//www. scipedia.com to download the version without the watermark

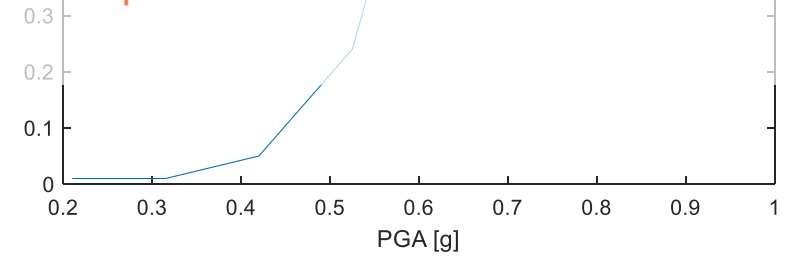

Figure 9: Fragility curve

For the majority of LHS analyses, the failure mode is either out-of-plane failure of the lateral walls of Unit 1, or flexural failure of the first storey piers of Unit 2. Which failure mechanism is dominant, depends on the set of material and modeling parameters. In case that out-of-plane damage is detected too early, the strengthening using the steel angles will be activated and the test continued. Examples of possible ultimate deformation states can be seen in Figure 10. 

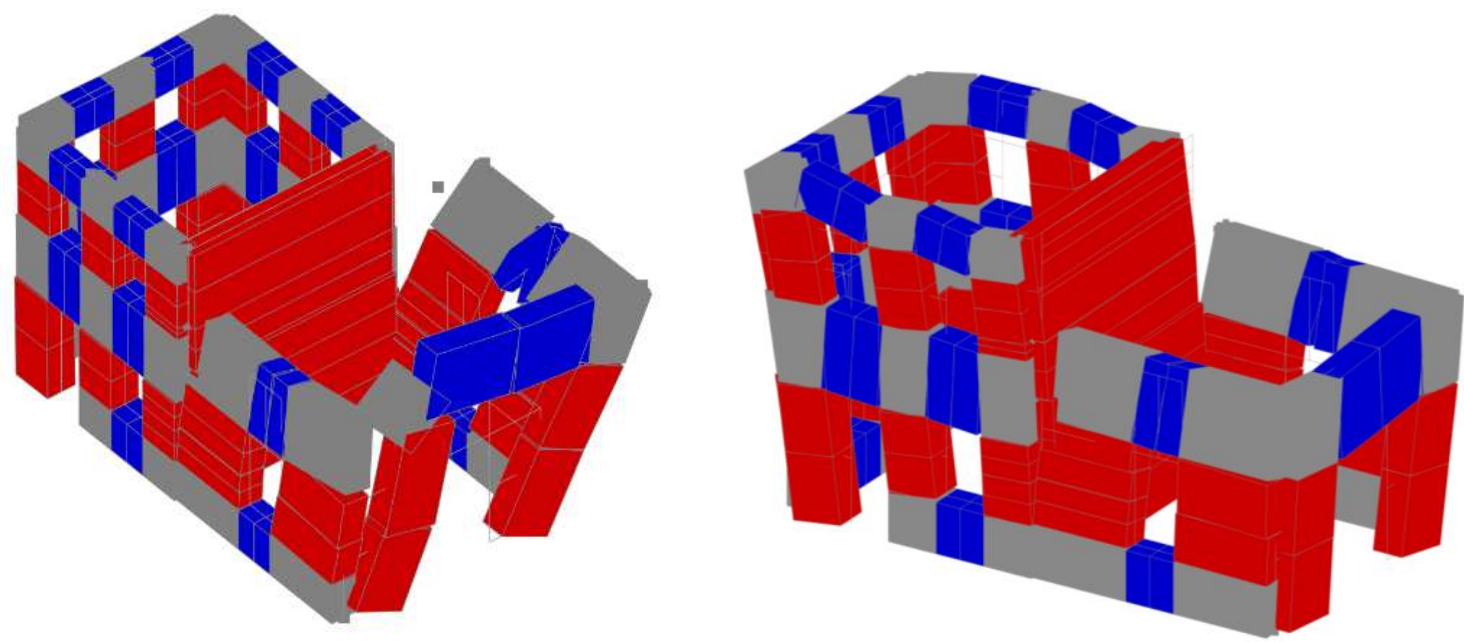

Figure 10: Examples of ultimate deformation states

\section{INSTRUMENTATION}

The behavior of the test specimen will be recorded using 40 accelerometers to record the accelerations of the foundation and the in-plane and out-of-plane accelerations of the masonry walls. 30 displacement transducers and an Optotrak LED optical measurement system will be used to monitor absolute displacements of chosen points and relative displacements of the interface between the units and relative displacements of the beams and the walls. Apart from the global behavior, special attention is paid to the interface behavior, in order to capture interaction and pounding between the adjacent units. The optical measurement system enables capturing displacements of multiple points with high precision.

\section{CONCLUSIONS}

In order to contribute to understanding the behavior of stone masonry building aggregates, a set of goals has been established for the experimental campaign of the AIMS project. Special attention was paid to the interface between the units, designed as a dry joint. Through numerical analyses, material and geometrical properties have been calibrated in order to fulfill the objectives, while respecting similitude laws and shake-table limits. The two units of the aggregate have been designed with different stiffnesses, floor orientations and added masses in order to facilitate different behavior and separation at the joint. Extensive instrumentation is planned in order to capture all the essential data. Numerical simulations were performed to predict the specimen's response and derive the numerical fragility curve. The experimental campaign is expected to contribute to the understanding of stone masonry aggregates behavior before and after separation of units, providing valuable data on the force-displacement response, interface behavior, pounding, damping and performance limits. It is accompanied by a blind prediction competition.

\section{ACKNOWLEDGMENTS}

The project leading to this application has received funding from the European Union's Horizon 2020 research and innovation programme under grant agreement No 730900. 


\section{REFERENCES}

[1] Guerrini, G., Senaldi, I., Scherini, S., Morganti, S. and Magenes, G. "Material Characterization for the Shaking-Table Test of the Scaled Prototype of a Stone Masonry Building Aggregate," presented at the XVII Convegno ANIDIS “l'Ingegneria Sismica in Italia," Pistoia, Italy, (2017).

[2] Senaldi, I., Guerrini, G., Caruso, M., Graziotti, F., Magenes, G., Beyer, K. and Penna, A. "Experimental Seismic Response of a Half-Scale Stone Masonry Building Aggregate: Effects of Retrofit Strategies," in Structural Analysis of Historical Constructions, (2019), pp. 1372-1381.

[3] Guerrini, G., Senaldi, I., Graziotti, F., Magenes, G., Beyer, K. and Penna, A. "Shake-Table Test of a Strengthened Stone Masonry Building Aggregate with Flexible Diaphragms," Int. J. Archit. Herit., pp. 1-20, (2019), doi: 10.1080/15583058.2019.1635661.

[4] Lagomarsino, S., Penna, A., Galasco, A and Cattari, S. "TREMURI program: An equivalent frame model for the nonlinear seismic analysis of masonry buildings," Eng. Struct., vol. 56, pp. 1787-1799, (2013), doi: 10.1016/j.engstruct.2013.08.002.

[5] Senaldi, I., Magenes, G. and Penna, A. "Numerical Investigations on the Seismic Response of Masonry Building Aggregates," Adv. Mater. Res., vol. 133-134, pp. 715-720, (2010), doi: 10.4028/www.scientific.net/AMR.133-134.715.

[6] Senaldi, I., Guerrini, G., Solenghi, M., Graziotti, F., Penna, A. and Beyer, K. "Numerical modelling of the seismic response of a half-scale stone masonry aggregate prototype", XVIII Convengno Anidis, (2019).

[7] Formisano, A., Castaldo, C. and Mazzolani, F.M. "Non-Linear Analysis of Masonry Building Compounds: A Comparison of Numerical and Theoretical Results," presented at the The Fourteenth International Conference on Civil, Structural and Environmental Engineering, Cagliari, Sardinia, Italy, p. 66, doi: 10.4203/ccp.102.66, (2013).

[8] Formisano, A., Florio, G., Landolfo, R. and Mazzolani, F.M. "Numerical calibration of an easy method for seismic behaviour assessment on large scale of masonry building aggregates," $A d v$. Eng. Softw., vol. 80, pp. 116-138, (2015), doi: 10.1016/j.advengsoft.2014.09.013.

[9] Maio, R., Vicente, R., Formisano, A. and Varum, H. "Seismic vulnerability of building aggregates through hybrid and indirect assessment techniques," Bull. Earthq. Eng., vol. 13, no. 10, pp. 2995-3014, (2015), doi: 10.1007/s10518-015-9747-9.

[10] Formisano, A. "Theoretical and Numerical Seismic Analysis of Masonry Building Aggregates: Case Studies in San Pio Delle Camere (L'Aquila, Italy)," J. Earthq. Eng., vol. 21, no. 2, pp. 227-245, (2017), doi: 10.1080/13632469.2016.1172376.

[11] Formisano, A. and Massimilla,A. "A Novel Procedure for Simplified Nonlinear Numerical Modeling of Structural Units in Masonry Aggregates," Int. J. Archit. Herit., vol. 12, no. 7-8, pp. 1162-1170, (2018), doi: 10.2080/15583058.2018.1503365.

[12] McKenna, F., Fenves, G.L., Scott, M.H. and Jeremic, B. Open System for Earthquake Engineering Simulation (OpenSees), (2000).

[13] Vanin, F., Penna, A. and Beyer, K. "A three-dimensional macro-element for modelling of the inplane and out-of-plane response of masonry walls", Earthquake Engineering \& Structural Dynamics, submitted for publication, (2020).

[14] Luzzi, L., Puglia, R. and Russo, E. Engineering Strong Motion Database, version 1.0. Istituto Nazionale di Geofisica e Vulcanologia, Observatories \& Research Facilities for European Seismology. doi: 10.13127/ESM. Orfeus WG5, (2016). 